\title{
AC 2007-2558: A COMPARISON OF STUDENT SOCIAL NETWORKS BETWEEN STUDENTS LIVING IN AND OUT OF LIVING LEARNING COMMUNITIES
}

\section{Shane Brown, Washington State University}

Karyn Hildreth, Washington State University

Graduate Student Department of Civil and Environmental Engineering Washington State University 
A Comparison of Student Social Networks between Students Living in and out of Living Learning Communities 


\begin{abstract}
Studies have shown that students who live in "Living Learning Communities" (LLCs'), i.e. places of residence where college students live among other students in the same field as their chosen major, are more likely to be retained in engineering programs than those who opt to live in general dorms or off campus. Existing research suggests that the social capital that students develop in these communities is influential in retention. Social capital is defined by World Bank as "the norms and social relations embedded in social structures that enable people to coordinate action to achieve desired goals". This study looks at the difference in the social networks of students who live in LLC's and those who do not. These social networks are used to measure the social capital gained by the students within Engineering. Seven freshmen engineering students, who will remain anonymous, at Washington State University participated in the study. Of these seven students, five of them live in Gannon-Goldsworthy, a math, science and engineering living learning community on campus, and the other two lived either in other dorms or off campus. Students' social networks and their activities with those around them were tracked over the course of term using weekly journals and information sessions. Students were asked to fill out a weekly journal that kept track of who they met, who they spent the most time with, and what they did with these people. In addition, weekly information sessions were held where the students discussed their weekly activities. The social networks of living learning community participants differed significantly from non LLC participants in both the number of engineering students in their networks and their closeness to other engineering students. Students living in Gannon-Goldsworthy had on average three close friends in engineering and four close friends not in engineering. Those who did not live in Gannon-Goldsworthy had an average of 2.5 friends in engineering and eight who were not in engineering. The data also suggests that students' close friends tend to live in the same residence hall as they do. Differences in students' social networks and activities suggest that with whom students interact and the degree of interaction with other engineering students may have a positive influence on retention of engineering students.
\end{abstract}

\title{
INTRODUCTION
}

There is a widespread shortage of engineers in the United States and it is important to develop programs that encourage the retention of students within engineering. The rapidly growing population requires engineers to continually come up with new methods for housing, feeding, health care, and more. Consequently, this parallels the need for more and more engineers in all branches. In turn, it becomes necessary to not only attract students to engineering, but to retain them in engineering. The dropout rate of engineers in the freshmen and sophomores years is significant ${ }^{12}$ and universities nationwide are looking at methods to keep engineering students in engineering. Retention in engineering is not only beneficial to the School of Engineering and Architecture, but also to industry.

\section{LITERATURE REVIEW}

Studies have shown that retention and student development are correlated with social integration $^{3}$. It has been suggested that a student's interaction with his peers is the single most important factor in student development ${ }^{1,2}$ and that the lack of peer group study is a significant factor regarding students changing majors from math, science and engineering fields in college ${ }^{14}$. Tinto's ${ }^{15}$ longitudinal model targets academic and social integration as a key reason for students dropping out of college programs as well. The literature clearly states that social integration in 
any setting, both academic and extracurricular, is key to the retention of students in higher education.

It is social capital, which is defined in this section, that is used to measure and analyze social integration ${ }^{3}$. Social capital is defined by the World Bank ${ }^{17}$ as "the norms and social relations embedded in social structures that enable people to coordinate action to achieve desired goals". Robert Putman ${ }^{13,14}$ claims that social capital is the compilation networks, norms, and trust within a social organization that facilitates coordination and cooperation for mutual benefit. It is important to understand that unlike financial capital in which once it is spent it is gone, the more we "spend" social capital, the more we gain. In effect, every time social capital is used, a potential for an increased stock of social capital exists ${ }^{3,6}$.

The concept of human capital is useful when considering social capital. Human capital is created by changes in persons that bring about skills and capabilities that make them able to act in new ways $^{5}$. For example, a secretary's knowledge of running office equipment makes he/she valuable to an engineering firm, a structural engineer brings his/her expertise of structural design and safety to the firm and an AutoCAD technician supplements the drafting necessities. In contrast to human capital, social capital resides in the relationships between individuals. In Robert Putman's book, Bowling Alone ${ }^{13}$, he addresses the issue of declining social capital in America. He points his finger at television as the cause of this dismaying trend. His research took place in the bowling alley, thus the title of his book. He found that less and less people participated in bowling leagues. However, it is not just bowling leagues that are suffering a decline in membership, Parent-Teacher Associations, extra-curricular sports, and other activities that require face-to-face teamwork and interaction are showing a marked decrease in volunteers. Social Capital is also shown to have an effect on economics. Francis Fukuyama ${ }^{11}$ claims that strong social capital between would be business partners results less in contracts and relies more on the goodwill of those involved. A lack of trust leads to costly contracts that are highly inflexible and restrictive. Contracts such as this exhibit a lack of trust between partners, and therefore a lack of social capital, and an increase in bureaucracy. This increase in bureaucracy in turn results in an increase in financial capital being used up. Fukuyama also notes in his article Social Capital and Development: The Coming Agenda ${ }^{10}$ that societies in which people cooperate and work together have a much higher chance of developing strong and efficient state institutions. This in turns limits economic interaction that could occur between cultural groups. Social Capital in the workplace has also received a fair amount of attention. In the book In Good Company ${ }^{4}$, UPS (United Postal Service) is looked at in regards to retention in the work place and its relationship to social capital. UPS is known for having a very low turnover rate. The waiting list to become a driver for the company is years long because employees do not leave the company. This is believed to be a consequence of the relationships between employees, and employees and employers. These good relationships developed because UPS has a horizontal hierarchy management system versus a vertical one. The horizontal system allows employees to feel like everyone they work with is a peer. Where a vertical hierarchy fosters suspicion and distrust, a horizontal system fosters trust and interaction. The social capital developed under this management system is very strong and has resulted in happy employees.

In 1988, James S. Coleman ${ }^{5}$ became the first researcher to tie social capital to drop-out rates in school. He correlated families that moved often to students that drop out of high school. His reasoning was that moving from school district to school district prevented the children from 
making strong social ties with their peers. This lack of social capital, more simply put, feeling left out and lonely, is more likely to result in students never receiving a high school diploma. Again, this results in an incomplete circle of social capital, human capital, and financial capital. The lack of education caused by low social capital leads to a lack of human capital, making it more difficult to store up financial capital.

The social capital between students in a certain major positively affect their success as a student, i.e. the possibility of retention in their chosen major is affected by the social networks that they develop $^{3}$. One way to develop a solid social network of engineering students is to have them reside in a living learning community where they are surrounded by their peers. While much research has been done on the effect of social capital in financial status, civic duty, the workplace, and education in general, studying social capital in LLCs' and its effect on retention has yet to be investigated explicitly. The purpose of this study is to investigate and compare student social capital for students living both in and outside of LLCs'.

\section{RESEARCH QUESTION}

Are the social networks of students living in a Living Learning Community (LLC) different than those living in other dorms or in apartments? How do the social networks differ between these two groups?

\section{RESEARCH SETTING}

Washington State University has a student population of approximately 23,000 statewide. The main branch is located in eastern Washington in the town of Pullman. The College of Engineering and Architecture (CEA) at the Pullman campus has just over 2500 students enrolled. Gannon-Goldsworthy is a LLC that has been established as a dorm for freshmen and sophomores in math, science, and engineering. There are 566 students living in Gannon-Goldsworthy and of those, 200 of them are enrolled in CEA. While students from other majors have the option of living there, math, science and engineering students have first priority. This LLC caters to these students by offering events such as career fairs, Society of Women Engineers meetings, and weekly Faculty Nights, where faculty members or graduate student in the CEA visit the dorm to talk to the students about their work, give them an opportunity to get to know the faculty, and begin to establish connections within the math, science and engineering community.

\section{RESEARCH PARTICIPANT SELECTION}

The study took place during the fall semester of 2006 and began in the seventh week of the semester. The study looked specifically at freshmen engineering students in their first semester at Washington State University. Students were recruited from Engineering 120, an introductory engineering course that encompasses all branches of engineering. In exchange for volunteering, the students were offered a pizza dinner once a week during focus group sessions and a $\$ 40.00$ gift certificate to Amazon.com or Starbucks at the end of the study.

There were 8 Engineering 120 courses with a class size of about 36 each. After a brief explanation of the project and incentives, a sign up list was sent around that asked the interested volunteers to indicate where they lived. Because WSU has a policy that all freshmen must live in dorms their first year, it made it much simpler to separate the students who opted to live in 
Gannon-Goldsworthy from those who did not. All volunteers who signed up were allowed to participate.

\section{DATA COLLECTION}

This study monitored freshmen students who have declared engineering as their intended major and consequently opted to live in the math science and engineering LLC. Their social networking was monitored through weekly written journals and information sessions. The same study was done simultaneously with freshmen students who opted to not live in GannonGoldsworthy. The LLC students were separated from the non-LLC students and a time was set up to meet with the two groups once a week for information sessions. Each week the students filled out a journal chronicling their activities such as studying, going to class and socializing. The journal consisted of a daily log that allowed the students to document their activities throughout each day and was handed out each week. This weekly journal also included a section where the volunteers listed the top five people they interacted with that week and in what capacity the interaction was: social only, study only, or social and study. The information sessions were set up to discuss these journals and gave the investigator the opportunity to obtain a more detailed description of their social networks for the week as well as information on their top five lists. The students were asked to talk about their top five people as well as anyone new that they had met that week. It was important to take note of who they knew, and if they knew anyone here at WSU before attending. All information sessions were recorded and Memory Stick Voice Editor software was used for transcription.

\section{DATA ANALYSIS}

Once the study was complete, the information session recordings were transcribed. With these transcriptions and the weekly journals, each volunteer's social network was analyzed and patterns in the social networks were investigated for each volunteer

\section{RESULTS}

The social networks of the LLC and non-LLC students were mapped out and then compared. It is important to note that the focus group meetings did not begin to take place until the seventh week of school.

The research that was completed suggested a noticeable difference in the networks between the two different groups being investigated. The Gannon-Goldsworthy residents spent drastically more time with students in their same majors and due to the voice inflections, etc. on the recordings were much less stressed regarding homework deadlines, and had more confidence in their school abilities and their decisions to major engineering. All of the LLC residents planned on continuing to reside in Gannon-Goldsworthy and all but one of the students were solidly decided on remaining in the engineering program.

The non-LLC group spent much more time with people in different majors, especially at the beginning of the semester. As the semester went by they gradually began spending more time with people in their major, but even then it was only with one or two other students. Only one of the students who did not live in Gannon-Goldsworthy was still firm in his decision to receive a degree in engineering. While the other student planned on finishing out their freshmen year in the program, they were still unsure whether they would be back for their sophomore year. In 
almost every case, their reasons for possibly switching majors were because all of the friends that they had made through the course of the semester were in a different major together. It is also important to note that the people they spent the most time with were people they lived with.

In both living situations, by the end of the semester the top five people that everyone spent the most time with had mostly become the same and the events where they met people also decreased. Patterns in social activity became apparent. Because this research is strictly anonymous and to protect my volunteers, their names have not been included. The following tables outline each student's patterns of social activities with all names changed due to confidentiality.

\section{LLC Students}

A. Student \#1 is a Bio-Engineering Major. She attended a prep school in Billings Montana that was specifically for students who wished to excel in math and science. She originally wanted to do Pre-Med in addition to Bio-Engineering but eventually changed her mind.

Table \#1: Student \#1, Social Network, Fall 2006

Student \#1, Bio-Engineering Major, Gannon-Goldsworthy Hall

\begin{tabular}{|l|l|l|l|}
\hline \multicolumn{1}{|c|}{ Name } & \multicolumn{1}{|c|}{ Major } & \multicolumn{1}{c|}{ Residence Hall } & Interaction \\
\hline Aaron & Agricultural Engineering & Ul Student & social/study \\
Erica & Spanish & Gannon-Goldsworthy & social/study \\
Christine & Nursing & Gannon-Goldsworthy & social/study \\
Molly & Creative Writing & Community & social/study \\
Karen & Undecided & Sorority House & social only \\
Matthew & Civil Engineering & Gannon-Goldsworthy & social/study \\
Kale & Chemical Engineering & Ul Student & social only \\
Melissa & Biology & Gannon-Goldsworthy & social/study \\
Abraham & Mechanical Engineering & Ul Student & social only \\
Melinda & Business & Off-Campus & social only \\
Ethan & Electrical Engineering & Ul Student & social only \\
\hline
\end{tabular}

B. Student \#2 was more on the quiet side and once he developed a circle of friends, it stayed that way, his social network rarely deviated. It is interesting to note however, that the group of people he had the most solid connection with was comprised primarily of other engineering students.

Table \#2: Student \#2, Social Network, Fall 2006

Student \#2, Civil Engineering, Gannon-Goldsworthy Hall

\begin{tabular}{|c|c|c|c|}
\hline Name & Major & $\begin{array}{c}\text { Residence } \\
\text { Hall }\end{array}$ & Interaction \\
\hline
\end{tabular}




\begin{tabular}{|l|l|l|l|}
\hline Robert & Mechanical Engineering & Stevenson & social/study \\
Steven & Chemical Engineering & Coman & social/study \\
Damian & Mechanical Engineering & Stevenson & social/study \\
Geoff & Civil Engineering & Stevenson & social/study \\
& & Gannon- & \\
Tyson & Chemistry & Goldsworthy & social only \\
Kevin & Chemical Engineering & Streit & social/study \\
& & Gannon- & \\
Teresa & Education & Goldsworthy & social/study \\
\hline
\end{tabular}

C. Student \#3 is Bio-Engineering and Pre-med student. When asked to write a list of the people he met when in the first few weeks of school, this student gave me the names of his usual top five and added the comment, "Yes, that's it. I am not very social". Though he was friendly and always added to the conversation, he was the most introverted of all of my students and appeared to make no effort or have any desire to widen his circle of friends. It is also interesting to note that while none of his close friends are actually engineering students, every single one of them live in his residence hall.

Table \#3: Student \#3, Social Network, Fall 2006

Student \#3, Bio-Engineering and Pre-Med Major, Gannon-Goldsworthy Hall

\begin{tabular}{|l|l|l|l|}
\hline \multicolumn{1}{|c|}{ Name } & \multicolumn{1}{|c|}{ Major } & \multicolumn{1}{c|}{ Residence Hall } & \multicolumn{1}{c|}{ Interaction } \\
\hline Nicholas & Pharmacy & Gannon-Goldsworthy & social/study \\
Antoine & Business & Gannon-Goldsworthy & social/study \\
Abram & Computer Science & Gannon-Goldsworthy & social/study \\
Terrence & Architecture & Gannon-Goldsworthy & social/study \\
Douglas & Business & Gannon-Goldsworthy & social/study \\
\hline
\end{tabular}

D. Student \#4 attended high school with student \#5 in Olympia, this particular high school put a strong emphasis on math, science and engineering and he took engineering classes at this school. These classes deepened his interest in Material Science and consequently he decided to pursue this in college. The bulk of Student \#4's social network consisted of people he went to high school with, including Student \#5. Interestingly, even though he interacted the most with this particular group, none of them were friends, or interacted at all in high school. The bonds they developed did not happen until they all went to college together. 


\begin{tabular}{|l|l|l|l|}
\hline \multicolumn{1}{|c|}{ Name } & \multicolumn{1}{|c|}{ Major } & \multicolumn{1}{c|}{ Residence Hall } & \multicolumn{1}{c|}{ Interaction } \\
\hline Student \#5 & Civil Engineering & Gannon-Goldsworthy & social/study \\
William & Mechanical Engineering & Gannon-Goldsworthy & social/study \\
Peter & Undecided & Gannon-Goldsworthy & social only \\
Jeremy & Business/Music & Gannon-Goldsworthy & social/study \\
Brandon & Business/Undecided & Gannon-Goldsworthy & social only \\
Brian & Pre-Med & Streit-Perham & social/study \\
\hline
\end{tabular}

E. Student \#5 attended the same high school as Student \#4 in Olympia that put a strong emphasis on math, science, and engineering, and also took engineering classes at this high school. As mentioned above, though all of these people went to the same high school and even had classes together, they did not interact until they went to college and all ended up living in the same LLC.

Table \# 5: Student \#5, Social Network, Fall 2006

Student \#5, Civil Engineering Major, Gannon-Goldsworthy Hall

\begin{tabular}{|c|c|c|c|}
\hline Name & Major & Residence Hall & Interaction \\
\hline Student \#4 & $\begin{array}{l}\text { Material Science } \\
\text { Engineering }\end{array}$ & Gannon-Goldsworthy & social/study \\
\hline William & Mechanical Engineering & Gannon-Goldsworthy & social/study \\
\hline Peter & Undecided & Gannon-Goldsworthy & social only \\
\hline Jeremy & Business/Music & Gannon-Goldsworthy & social/study \\
\hline Brandon & Business/Undecided & Gannon-Goldsworthy & social only \\
\hline Brian & Pre-Med & Streit-Perham & social/study \\
\hline Celine & English & Streit-Perham & social only \\
\hline
\end{tabular}

\section{Non-LLC Students}

F. Student \#6 is a Bio-Engineering major who lives in Stevens Hall, an all female student dorm. She is actively involved in Campus Christian Fellowship (CCF) and weekly bible study's that take place in her dormitory. The majority of the people she interacted with the most are people that she met in these groups. She admitted to interacting very little with others in her classes and preferred to study and do her homework alone, though by the end of the semester she was beginning to study with other people in her classes, specifically Chemistry.

Student \#6 interacted very little with other students in her Engineering 120 class and also expressed frustration with the lack of other female students in engineering. She was uncertain 
how to interact with a mostly male classroom and felt as if she didn't connect with anyone in engineering. Her frustration grew even more due to the fact that almost all of the friends she had made were all in another major and had their classes together. Her doubts concerning these things made her question the major she had chosen. Shortly before Thanksgiving however, she met another female bio-engineering major and her excitement about her education in this field was renewed.

Table \#6: Student \#6, Social Network, Fall 2006

Student \# 6, Bio-Engineering Major, Stevens Hall

\begin{tabular}{|l|l|l|l|}
\hline \multicolumn{1}{|c|}{ Name } & \multicolumn{1}{|c|}{ Major } & Residence Hall & Interaction \\
\hline Alyssa & Architecture & Stevens & social/study \\
Allison & Communications & Stevens & social only \\
Lorraine & Political Science & Off campus & social only \\
Elise & Civil Engineering & Regents & social only \\
Amanda & not in college & Off campus & social only \\
Cara & Music & Off campus & social only \\
Kelly & Nursing & Honors & social only \\
Margaret & Counseling \& Psychology & Off campus & social/study \\
Bonnie & Animal Sciences/pre-vet & Stevens & social/study \\
Susie & Interior Design & Off campus & social only \\
\hline
\end{tabular}

G. Student \#7 is a Mechanical Engineering student and lives in Honors Hall. He is probably the most socially oriented of all the volunteers and is very friendly and outgoing. Almost all of his friends were people he only socialized with; he rarely ever studied with them.

Table \#7: Student \#7, Social Network, Fall 2006

Student \#7, Mechanical Engineering Major, Honors Hall

\begin{tabular}{|l|l|l|l|}
\hline Name & \multicolumn{1}{|c|}{ Major } & $\begin{array}{l}\text { Residence } \\
\text { Hall }\end{array}$ & Interaction \\
\hline Seth & Philosophy & Honors & social/study \\
Jonah & Communication & Honors & social only \\
Breanna & Architecture & Honors & social only \\
Lisa & Chemistry & Honors & social only \\
Becca & Physics & Honors & social only \\
Jordan & Mechanical Engineering & Honors & social only \\
Emily & Civil Engineering & Honors & social only \\
Kristofer & Animal Science/Pre-Vet & Honors & social/study
\end{tabular}




\begin{tabular}{|l|l|l|l|} 
Michael & Mechanical Engineering & Honors & social/study \\
Joe & Civil Engineering & Honors & social/study \\
Marcus & Psychology & Honors & social only \\
\hline
\end{tabular}

Overall Results

In almost every case in this study, the volunteering students' social networks evolved primarily in their places of residence. They dined with, studied with, watched T.V. with, and interacted with the most with those who lived around them as recorded in their weekly journals. Therefore, the volunteers in this study who lived in Gannon-Goldsworthy spent much of their time with students in math, science, and engineering majors. The students who did not live in GannonGoldsworthy took almost all semester to meet other engineering students despite the fact that they were enrolled in Engineering 120, an entry level class for beginning engineers just like themselves. This also held true for the Gannon-Goldsworthy residents, they did not make friends with other young engineers in this class; they almost exclusively met other engineers in their dorm. The following table details the average number of engineering students that each participant spent peer development and study time with

Though the investigation called for twenty volunteers, ten in each category, which I originally had, the volunteers dwindled from ten to five in the Gannon-Goldsworthy group and fifteen to two in the non-Gannon-Goldsworthy group. Because of the small sample size of the two groups it is difficult to make solid correlations in the students social networks and the results are situational.

The other drawback to this investigation was its late start. The first focus group did not happen until the first week of October. This study will be repeated next fall and will begin by the second week of the semester.

Table \#8: LLC Participants vs. Non-LLC participants

\begin{tabular}{|l|c|c|}
\hline & $\begin{array}{c}\text { Gannon-Goldsworthy } \\
\text { Residents }\end{array}$ & $\begin{array}{c}\text { Non-Gannon Goldsworthy } \\
\text { Residents }\end{array}$ \\
\hline $\begin{array}{l}\text { Average \# of close } \\
\text { friends in engineering }\end{array}$ & 3 & 2.5 \\
\hline $\begin{array}{l}\text { Average \# of close } \\
\text { friends who live in the } \\
\text { same dorm }\end{array}$ & 4.2 & 7 \\
\hline $\begin{array}{l}\text { Average \# of close } \\
\text { friends in engineering } \\
\text { that participants study } \\
\text { with }\end{array}$ & 2.8 & 1 \\
\hline $\begin{array}{l}\text { Average \# of close } \\
\text { friends not in } \\
\text { engineering }\end{array}$ & 4 & 8 \\
\hline
\end{tabular}




\section{CONCLUSIONS}

The results provide a positive correlation between social networks among engineering students and retention within engineering. It is clear that as students develop attachments to other students they are more likely to remain in the situation in which they have entered. It would be beneficial to the WSU department of Engineering and Architecture to encourage first year students to live in Gannon-Goldsworthy.

While this is just one reason why students who live in LLCs' have a higher retention than those who don't, it is clear that the attitudes regarding engineering are much more positive when there is strong social network developed among peers.

\section{CITATIONS}

1. Astin, A.W., "Involvement in Learning Revisited: Lessons We Have Learned," Journal of College Student Development, vol. 40, pp. 587-598, 1999.

2. Astin, A.W., What Matters in College? : Four Critical Years Revisited 1st ed. San Francisco: Jossey-Bass, 1993.

3. Brown, Shane, Social Capital in Education, Doctoral Dissertation, Oregon State University. 2005.

4. Cohen, D and Prusak, L., In Good Company: How Social Capital Makes Organizations Work (Boston MA: Harvard Business School Press, 2001)

5. Coleman, James S. "Social Capital in the Creation of Human Capital." American Journal of Sociology, Supplement 1988, 94, pp. S95-120.

6. Cox, E., A Truly Civil Society: Lecture 2, Raising Social Capital. The 1995 Boyer Lectures

7. Gradstein, Mark and Justman, Moshe. "Human Capital, Social Capital, and Public Schooling." European Economic Review, May2000, 44(4-6), pp. 879-90.

8. Gradstein, Mark and Justman, Moshe. "Education, Social Cohesion, and Economic Growth." Centre for Economic Policy Research (London) Discussion Paper No. 2723, 2001

9. Granovetter, M.S., "The Strength of Weak Ties," American Journal of Sociology 78 (1973): 1360-80.

10. Fukuyama, F., "Social Capital and Development: The Coming Agenda," SAIS Review, (2002) V22, No. 1 pp. 23-37.

11. Fukuyama, F., Trust: The Social Virtues and the Creation of Prosperity (New York: Free Press, 1995)

12. Light, Jenny, Developing and Assessing a Holistic Living-Learning Community for Engineering and Science Freshmen. Doctoral Dissertation, Washington State University, 2005.

13. Putnam, R, D., Bowling Alone: The Collapse and Revival of American Community (New York: Simon and Schuster, 2000).

14. Putnam. R, D., Bowling Alone: America's declining social capital. Journal of Democracy 1995; 6:65-78. 
15. Seymour, E and Hewitt, N.M, Talking About Leaving: Why Undergraduates Leave the Sciences. Boulder, CO: Westview Press, 1997.

16. Tinto, V., Leaving College: Rethinking the Causes and Cures of Student Attrition. Chicago: University of Chicago Press, 1987.

17. World Bank Social Capital. Website http://www.worldbank.org/poverty/scapital/index.htm 